\title{
CovID-19 COVID-19 recognition and digital risk stratification
}

\author{
Authors: Luke E Hodgson, ${ }^{\mathrm{A}}$ Todd Leckie, ${ }^{\mathrm{B}}$ Alexander Hunter, ${ }^{\mathrm{C}}$ Nicolaas Prinsloo, ${ }^{\mathrm{D}}$ Richard Venn ${ }^{\mathrm{E}}$ and Lui Forni ${ }^{\mathrm{F}}$
}

In the acute hospital setting the COVID-19 pandemic presents some unique challenges to acute patient care. These include accurate recognition of cases, confirmation of both testing requests and results, establishing patient acuity and alerting to deterioration. We report our experience introducing a digital COVID-19 assessment tool with an associated live dashboard at two acute NHS hospitals, enabling accurate hospital-level reporting alongside risk stratification.

KEYWORDS: Digital assessment, COVID-19, coronavirus

DOI:10.7861/fhj.2020-0037

\section{Introduction}

The COVID-19 pandemic caused by the novel severe acute respiratory syndrome coronavirus SARS-CoV-2 is a global healthcare emergency. ${ }^{1}$ Since the first described cases in the UK at the end of January 2020, the NHS has had to respond rapidly to this new disease. ${ }^{2}$ At our hospital trust it was clear, following initial experience, that accurate reporting and hospital-wide visualisation of patients with suspected and confirmed COVID-19 would be crucial for the optimal management of our local response. This brief report outlines the steps taken to provide a digital real-time overview of our caseload.

Up until the end of March, testing for our population was performed at another trust with a turnaround time in days. The majority of COVID-19 swab samples were performed by emergency department (ED) staff and sent to the laboratory to be 'booked in' and dispatched to the testing site. Out of hours there was the potential for delays in visualisation of 'booking in' status and of test results. Although the number of tests and those positive could be reviewed on a trust level, this was not in a 'live' format.

\section{Interventions}

For a number of years, the Trust has used the track-and-trigger system Patientrack Alcidion ${ }^{\circledR}$ for real-time electronic physiological

Authors: Aintensive care and respiratory consultant, Worthing Hospital, Worthing, UK and visiting senior lecturer, University of Surrey, Guildford, UK; ${ }^{B}$ anaesthetic registrar, Worthing Hospital, Worthing, UK; ' Canaesthetic CT3, St Richard's Hospital, Chichester, UK; Dinformatics fellow, Worthing Hospital, Worthing, UK; Eintensive care consultant, Worthing Hospital, Worthing, UK; Fintensive care consultant, Royal Surrey County Hospital Guildford, UK and professor, University of Surrey, Guildford, UK

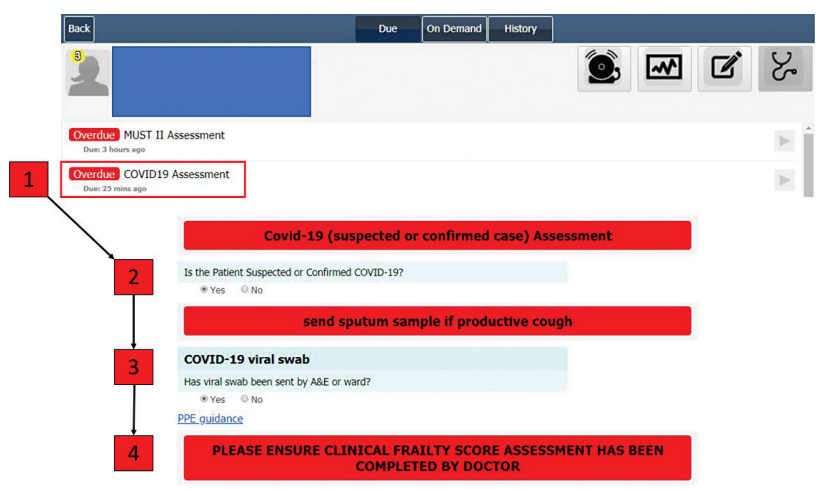

Fig 1. Individual COVID-19 assessment interface. This is accessed from the individual patient tile; once submitted the patient is automatically transferred into the live dashboard COVID-19 report.

observations and other assessments, such as frailty, malnutrition and dementia. This platform was utilised to rapidly produce a mandatory COVID-19 assessment to be completed by nursing staff at the point of admission to hospital (as the ED team work on paper charting), produced in consultation with our microbiology and infection control team. All patients receive the admission assessment and, for those not suspected of having COVID-19, a single click selection of the 'not suspected' field is all that is required. We employed recommended methods for clinical decision support to optimise compliance and avoid undue disruption to the clinical workflow. ${ }^{3}$ Fig 1 shows the assessment within the Patientrack architecture. This includes a prompt to complete a frailty assessment as per NICE guidance. ${ }^{4}$

\section{Live dashboard report with physiological risk stratification}

To enable hospital-wide visualisation of patients suspected and confirmed to have COVID, a live dashboard was created. Once the COVID-19 assessment is submitted, the patient details are automatically entered into the dashboard, which then automatically updates once a COVID-19 result is returned through the laboratory reporting system (Fig 2).

Early reports from China suggest that COVID-19 may necessitate more nuanced ways of highlighting those at highest risk, with the performance of traditional scoring systems such as the National Early Warning Score 2 (NEWS-2) as yet unclear. For example, blood pressure, heart rate and temperature do not differ significantly between those with severe and non-severe disease. ${ }^{5-7}$ To date, 


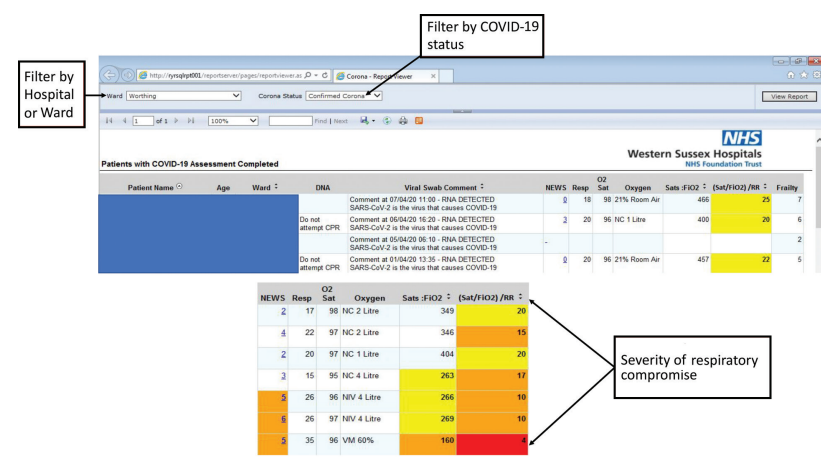

Fig 2. COVID-19 report interface. This live dashboard highlights location of patient, test status (suspected, awaiting test, confirmed), latest physiological variables and clinical frailty scale assessment.

there are no recommended prediction models to help stratify risk, with a systematic review finding all prognostic models at high risk of bias. ${ }^{8}$ However, previous studies have suggested that the ratio of oxygen saturations to (approximate) concentration of oxygen delivered $\left(\mathrm{SpO}_{2}: \mathrm{FiO}_{2}\right)$ is a good surrogate of the $\mathrm{PaO}_{2}: \mathrm{FiO}_{2}$ used in the critical care environment, 9,10 and could potentially be used as an electronically calculated variable to alert clinical teams to deterioration. $\mathrm{SpO}_{2}: \mathrm{FiO}_{2}$ values have been proposed ${ }^{11}$ as:

> 235-314: mild impairment

$>$ 150-234: moderate impairment

$><150$ : severe impairment.

A further enhancement of respiratory risk stratification could include the respiratory rate ([ $\left.\mathrm{SpO}_{2}: \mathrm{FiO}_{2}\right] /$ respiratory rate), termed the ROX score, which has been derived and externally validated to predict failure of nasal high flow therapy (defined as requirement for intubation). ${ }^{12,13}$ A value $>4.88$ predicts those less likely to require intubation. We have employed a colour-coded system (yellow, amber, red) to highlight patients with extremes of respiratory dysfunction using both of these methods, which can aid visualisation of patients in the busy clinical environment (Fig 2).

Numerous other scores in this area include the Murray score, described in 1988, which comprises quadrants infiltrated on the chest radiograph, degree of hypoxaemia, positive end-expiratory pressure (PEEP) and static compliance of the respiratory system. ${ }^{14}$ The Murray score is more suitable for critical care patients - for example, those undergoing consideration for extracorporeal membrane oxygenation (ECMO) - as is the respiratory extracorporeal membrane oxygenation survival prediction (RESP) score. ${ }^{15}$ The MuLBSTA score was published last year from a Chinese viral pneumonia cohort, and comprises multi-lobar infiltrates, lymphopenia, bacterial co-infection, current or ex-smoker, hypertension and age; however, this score has limited validation. ${ }^{16}$

\section{Education and awareness}

On the basis of previous experience in introducing assessments, we used a combination of Trust communications (email and paper 'Weekly headlines', 'Theme of the week', and desktop alerting), daily staff huddles, and meetings with doctors and nurses and the outreach nursing team on both acute hospital sites. An iterative process was employed to optimise completion and clinical utility.

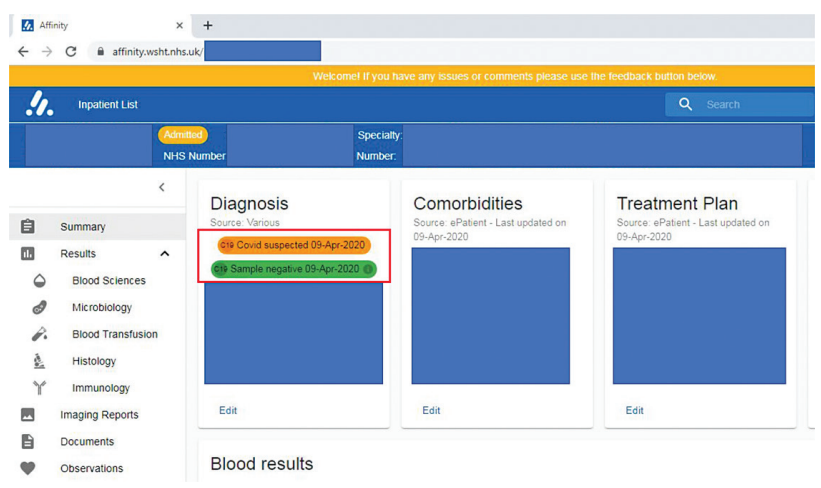

Fig 3. Clinical portal used by the clinical team. COVID-19 swab status is included as part of handover and task management.

\section{Issues and feedback}

As with any IT implementation project, user input was crucial to ensure acceptability and success. Firstly, following feedback from clinical teams, the assessment was significantly shortened to the current version, having previously had additional information requirements, including reporting of symptoms and whether other investigations had been performed. Secondly, as doctors at our Trust predominantly use a separate e-handover system for their clinical workflow, a second solution was developed in tandem to display information regarding COVID samples for clinical visualisation within the clinical portal (Fig 3). Thirdly, if a patient were to develop new symptoms on the ward prompting investigation for COVID-19, the ward team would have to complete a second digital assessment as the initial admission assessment would place the patient in the 'COVID not suspected' cohort. This has required ongoing education by the outreach clinical teams. Between go-live on the 23 March 2020 and 9 April 2020, 1,270 patients had an assessment performed, with a positive response from ward and outreach clinical teams to the package that has been introduced. In addition, a system of ensuring clear documentation of investigations requested by the ED team was required to prevent duplication or omission; this system rapidly evolved from a stamp on the front of the paper clerking notes to a bespoke COVID-19 ED clerking proforma.

\section{Conclusions}

We describe a simple digital COVID-19 assessment that has provided our clinical teams and hospital management with up-todate information during a rapidly changing clinical situation.

\section{Acknowledgements}

The authors would like to thank Tim Short, information analyst, for invaluable work integrating the COVID-19 report and Donald Kennedy and Jamie Hobdell at Alcidion for their help in introducing the COVID-19 assessment.

\section{References}

1 Ghebreyesus T. WHO director-general's opening remarks at the media briefing on COVID-19 - 11 March 2020. www.who.int/dg/ speeches/detail/who-director-general-s-opening-remarks-at-the- 
media-briefing-on-covid-19-11-march-2020 [Accessed 09 April 2020].

2 Kinross P, Suetens C, Gomes Dias ] et al. Rapidly increasing cumulative incidence of coronavirus disease (COVID-19) in the European Union/European Economic Area and the United Kingdom, 1 January to 15 March 2020. Euro Surveill 2020;25:2000285.

3 Bates DW, Kuperman G], Wang S et al. Ten commandments for effective clinical decision support: making the practice of evidence-based medicine a reality. J Am Med Inform Assoc 2003;10:523-30.

4 National Institute for Health and Care Excellence. COVID-19 rapid guideline: critical care. NG159. NICE, 2020. Available from www. nice.org.uk/guidance/ng159/resources/covid19-rapid-guidelinecritical-care-pdf-66141848681413 [Accessed 09 April 2020].

5 Wang D, Hu B, Hu C et al. Clinical characteristics of 138 hospitalized patients with 2019 novel coronavirus-infected pneumonia in Wuhan, China. JAMA 2020;323:1061-9.

6 Zhou F, Yu T, Du R et al. Clinical course and risk factors for mortality of adult inpatients with COVID-19 in Wuhan, China: a retrospective cohort study. Lancet 2020; 395:1054-62.

7 Yang X, Yu Y, Xu J et al. Clinical course and outcomes of critically ill patients with SARS-CoV-2 pneumonia in Wuhan, China: a single-centered, retrospective, observational study. Lancet Resp Med 2020;8:477-81.

8 Wynants L, Van Calster B, Bonten MMJ et al. Prediction models for diagnosis and prognosis of Covid-19 infection: systematic review and critical appraisal. BMJ 2020;369:m1328.

9 Lobete C, Medina A, Rey C et al. Correlation of oxygen saturation as measured by pulse oximetry/fraction of inspired oxygen ratio with $\mathrm{PaO}_{2} /$ fraction of inspired oxygen ratio in a heterogeneous sample of critically ill children. J Crit Care 2013;28:538.e1-7.
10 Khemani RG, Thomas NJ, Venkatachalam V et al. Comparison of $\mathrm{SpO}_{2}$ to $\mathrm{PaO}_{2}$ based markers of lung disease severity for children with acute lung injury. Crit Care Med 2012;40:1309-16.

11 Adams JY, Rogers AJ, Schuler A et al. Association between peripheral blood oxygen saturation $\left(\mathrm{SpO}_{2}\right)$ /fraction of inspired oxygen $\left(\mathrm{FiO}_{2}\right)$ ratio time at risk and hospital mortality in mechanically ventilated patients. Perm J 2020;24:19.113.

12 Roca O, Caralt B, Messika J et al. An index combining respiratory rate and oxygenation to predict outcome of nasal high-flow therapy. Am J Respir Crit Care Med 2019;199:1368-76.

13 Roca O, Messika J, Caralt B et al. Predicting success of high-flow nasal cannula in pneumonia patients with hypoxemic respiratory failure: The utility of the ROX index. J Crit Care 2016;35:200-5.

14 Murray JF, Matthay MA, Luce JM, Flick MR. An expanded definition of the adult respiratory distress syndrome. Am Rev Respir Dis 1988;138:720-3.

15 Schmidt M, Bailey M, Sheldrake ] et al. Predicting survival after extracorporeal membrane oxygenation for severe acute respiratory failure: the Respiratory Extracorporeal Membrane Oxygenation Survival Prediction (RESP) score. Am J Respir Crit Care Med 2014; 189:1374-82.

16 Guo L, Wei D, Zhang X et al. Clinical features predicting mortality risk in patients with viral pneumonia: the MuLBSTA Score. Front Microbiol 2019;10:2752.

Address for correspondence: Dr Luke Hodgson, Worthing Hospital, Lyndhurst Rd, Worthing, Sussex BN11 2DH, UK. Email:drlhodgson@gmail.com 